\title{
Reseña viaje a USA, noviembre 2018
}

\author{
Luis Mauricio Albornoz \\ Doctor en Teología \\ Universidad Católica del Maule \\ malbornoz@ucm.cl
}

Como citar este artículo: L.M. ALBORNOZ “Reseña viaje a USA, noviembre 2018” en Palabra y Razón. Revista de Teología, Filosofia y Ciencias de la Religión No16, Diciembre 2019, pp. 109-112 https://doi.org/10.29035/ pyr.16.109

En noviembre pasado (2018) estuve en una visita de investigación en el National Institute of Newman Studies, organismo norteamericano dedicado a profundizar y promover la obra del pensador Inglés decimonónico, John Henry Newman, canonizado por la Iglesia (13 de octubre 2019). Newman, en efecto, fue un autor prolífico cuyo pensamiento ha impactado el desarrollo teológico del siglo XX, así como lo hizo en su propio tiempo. Ubicado en la localidad de Pittsburg, USA, el NINS, conocido así por sus siglas en Inglés, se encuentra ahora trabajando en los manuscritos originales de este autor, que se encontraban en la localidad de Birmingham Inglaterra donde Newman vivió la segunda mitad de su vida. La idea de la visita era socializar lo que en habla hispana y en particular en Latinoamerica se esta haciendo para promover y cultivar el pensamiento y aporte con el que este pensador inglés ha contribuido al quehacer, filosófico, ético, educacional y teológico.

Como breve referencia de este centro señalemos que en el año 2000, el fundador de la Venerable John Henry Newman Association (actualmente, la Newman Association of America), el Padre Vincent J. Giese, deja este mundo, ofreciendo como legado un gran capital bibliográfico entorno a las obras de Newman. Luego en el año 2002, el p. Drew Morgan, C.O., y la Sra. Catharine M. Ryan, miembros de la junta directiva de la Asociación, comenzaron a formular una idea que permitiera favorecer con frutos el legado que el Padre Giese habia otorgado. Imaginaron un centro donde los académicos pudieran acceder a los documentos y materiales relacionados con Newman y de Newman. El Instituto fue concebido como un foro para intercambiar ideas y descubrimientos sobre el pensamiento de Newman y su relevancia continua. 
Con la ayuda de muchos amigos generosos y serviciales, vieron crecer su idea en el Instituto Nacional de Estudios de Newman. La colección Giese se llevó a Pittsburgh en 2002. Desde entonces, el Instituto se ha instalado allí ofrecidendo a la academia y a la socialización de la emblemática figura de Newman muchos logros.

A este lugar fui como académico de la Facultad de Ciencias Religiosas y Filosóficas de la Universidad Católica del Maule y en calidad de Vicepresidente del Círculo Newman, grupo de amigos de habla española, procedentes de América y Europa. Cada uno de los miembros del círculo ha ido estudiando un aspecto del pensamiento de John Henry Newman (1801-1890). Señalemos que el nombre de Newman está ligado a una gran gama de ámbitos, desde el intelectual de la filosofía, la teología, la poesía, la música; el educativo, el político, el social y particularmente, el religioso puesto que fue uno de los gestores de la revitalización de la Iglesia Anglicana y, posteriormente, el converso inglés al catolicismo más relevante de su época.

El Círculo Newman tiene interés en promover el pensamiento de Newman desde los autores que inspiraron sus reflexiones, como Cicerón o Joseph Butler; o desde sus discípulos intelectuales, como Maurice Nedoncelle, Bertrand Lonergan o Joseph Ratzinger.

Uno de nuestros objetivos es ir acrecentando y fortaleciendo la red de expertos y la comunicación para incursionar en la profundización y divulgación de temas relacionados con la educación, la filosofía, la teología, la historia, la literatura... todo ello vinculado de alguna manera con Newman. Es por esta razón que mi viaje consideró la socialización del trabajo investigativo que llevo adelante desde Talca, Chile, y en particular favorecer con ello la presencia de nuestra facultad y Universidad en tierras nosrteamericanas.

En efecto, como círculo hemos estado impulsando proyectos como la traducción del inglés, $u$ otras lenguas, al castellano de obras relacionadas con Newman, sus fuentes y comentadores, procurando añadir comentarios que hagan más fácil su comprensión. Se impulsan tesis sobre estos temas con el fin de ser fieles al pensamiento de este destacado autor.

En el citado viaje a Pittsburg aprovechamos de presentar el trabajo de algunos miembros del Círculo. El primero de ellos fue la traducción del francés al castellano que realizó Pedro Benítez del libro Creo en Ti de Jean Mouruox, publicado en Ediciones PROMESA, Costa Rica 2014. El segundo libro se titula Creemos porque amamos, y fue presentado por su autor, Juan Carlos Mayorga Enríquez. Publicado por Editorial San Pablo, México. 
En editorial Promesa hemos publicado de mi autoría: Ciencia positiva y fe religiosa: caminos hacia el conocimiento. Y recientemente, el año 2018 Hacia una verdadera religión: la propuesta de John Henry Newman.

Aprovechamos dicha instancia para socializar con el NINS los distintos eventos que hemos organizado con el fin de favorecer la divulgación y promoción de esta figura de la Iglesia, nos hemos podido reunir un buen número de nosotros en octubre 2015 los días 8, 9 y 10 en las instalaciones de la Universidad Panamericana, Campus Guadalajara. En el mismo mes de octubre del año 2017 lo hicimos en Talca, Chile, en nuestra Universidad Católica del Maule, y en unos meses más, también en Octubre, lo haremos en la Universidad de Navarra, España. El proximo día 13 de octubre, poco antes de nuestro congreso, el Papa Francisco canonizará al beato Newman en Roma.

Volviendo a la vida del NINS, señalemos que actualmente esta presidido por Ryan ("Bud") Marr quien es además Editor Asociado del Newman Studies Journal desde septiembre de 2017. Es el autor de To Be Perfect is To Changed (El desarrollo de la perspectiva eclesiológica de John Henry Newman). 1845-1877 (Rowman \& Littlefield, 2018), y también ha contribuido con Ensayos entorno al pensamiento de Newman, su vida y su espiritualidad, algunos títulos de su autoría son: Life in the Spirit (Fortress Press, 2014), Learning from All the Faithful (Pickwick, 2016) y The Oxford Handbook of John Henry Newman ( Oxford University Press, 2018). Antes de mudarse a Pittsburgh, el Dr. Marr enseñó durante tres años en Mercy College of Health Sciences en Des Moines, IA. Sus intereses de investigación incluyen la vida y los escritos de John Henry Newman, la eclesiología y la recepción del Concilio Vaticano II.

Con el director del instituto pudimos tener una larga entrevista que permitió intercambiar ideas y planes respecto a lo que se puede avanzar en intercambio y trabajo conjunto desde habla hispana. En particular lo que se refiere a la Universidad Católica del Maule, y a la Facultad de Ciencias Religiosas y Filosóficas abrimos la posibilidad de concretar pasantías de investigación gestionadas y financiadas por el NINS, para nuestros estudiantes y profesores. La idea es que en el próximo tiempo este tipo de actividades se puedan ir concretando para favorecer la internacionalización y potenciar aún más la investigación en nuestra Facultad.

En efecto el Instituto Nacional de Estudios de Newman ofrece un Programa de Becas Visitas para académicos que desean dedicar un período de investigación, de 2 a 8 semanas, y escribir en el campo de Estudios de Newman. Los candidatos para este programa son admitidos en dos niveles, contemplando un aporte económico directo al becario, además del alojamiento en el instituto. El Instituto hace una clasificación para sus becarios de acuerdo a dos grandes niveles: 
Experto Académico en Newman: Formulario de evaluación de salida e informe narrativo del proyecto que detalla el progreso hacia la finalización del proyecto propuesto y el resumen de los resultados, así como un documento de investigación basado en el trabajo realizado en el Instituto.

Desarrollando Newman Scholar: El Formulario de evaluación de salida y un Informe narrativo que detalla el progreso hacia la finalización del proyecto propuesto y el resumen de resultados, así como un documento de investigación basado en el trabajo realizado en el Instituto.

Además, todos los becarios deben completar una entrevista final con el Director y presentar una carta de evaluación sobre el programa.

Los académicos deben enviar todos los materiales requeridos dentro de los treinta días posteriores a la finalización de su tiempo en NINS. El pago del estipendio se enviará después de que el Director reciba y apruebe estos materiales. Para el beneficio tanto del académico como del personal administrativo del NINS, todos los materiales deben enviarse, al mismo tiempo, como documentos de Word / PDF y deben adjuntarse a un solo correo electrónico.

Como se ve, se hace posible a partir de esta visita iniciar caminos de profundización, estuidio e investigación, a partir de lo que en Chile podemos profundizar y materializar entorno a este autor inglés, es de esperar que la proxima canonización favorezca aún más el compromiso y la sensibilidad por conocer su persona y su vida. 